\title{
INFORME SOBRE IMPROCEDENCIA EN LA INDIVISIÓN HEREDITARIA DE EFECTUAR UNA PARTICIÓN PARCIAL A FAVOR DE UN COMUNERO, MANTENIENDO LA COPROPIEDAD ENTRE LOS RESTANTES
}

\section{Jorge López Santa María}

Doctor por la Universidad de París, (única en 1968)

Profesor Titular de Derecho Civil, Universidad de Chile

Este breve informe fue preparado a solicitud del abogado y profesor José Joaquín Ugarte Godoy, para ser presentado en el juicio particional caratulado Inmobiliaria Security con Hortensia Nieto Varas y otros, que se tramitaba ante el árbitro Miguel Leighton Puga, hoy concluido.

Para emitir mi informe tuve a la vista el segundo otrosí del escrito del 28 de agosto del año 2008 , rolante a foja 259 y ss. de los autos arbitrales, suscrito por José Joaquín Ugarte Godoy en representación de Inmobiliaria Security, cuyo contenido, en mi opinión, es irrefutable. También leí el informe en Derecho titulado "Partición de comunidad en un predio", fechado 6 de octubre de 2008, del cual es autor René Abeliuk Manasevich, por la sociedad de profesionales René Abeliuk Manasevich y Cía., cuyo tenor y conclusión comparto.

En el segundo otrosí del escrito precitado, se expresó, textualmente:

"Segundo Otrosí: Ruego a Vuestra Señoría tener presente las razones que paso a exponer acerca de que la división de un cuerpo cierto en naturaleza, es decir, en partes físicas, en la partición de comunidad, sólo es posible jurídicamente si pueden hacerse de ese cuerpo cierto, en nuestro caso, el predio de autos, tantos lotes como comuneros haya, sin que sea dable hacer la división formando un lote para un comunero y otro para todos los demás considerados como un conjunto.

I) En el fondo, lo que han planteado en nuestro caso los restantes comuneros, o algunos de ellos, en el sentido de que será posible la cómoda división, si es factible hacer un lote para mi representada y otro para todos ellos en conjunto, es simplemente que se haga una partición parcial sin que haya un acuerdo unánime para proceder de esa manera. Pues bien, en los siguientes numerandos paso a demostrar que ello no es jurídicamente posible; 
II) En primer lugar, la ley ve la comunidad con malos ojos y establece la acción de partición para que cualquiera de los indivisarios pueda terminar totalmente con la comunidad, sin hacer distingos acerca de si hay algunos comuneros que desean que lo que a ellos pueda caberles se mantenga entre ellos en comunidad;

III) Los pactos de indivisión sólo valen si son escritos y si se refieren a la totalidad de los comuneros;

IV) La ley no quiere ni contempla que pueda haber primero una pequeña partición y después otra;

V) La garantía de la igualdad-que es esencial a las particiones- está en que todos los comuneros corran la misma suerte. Ahora bien, ello no queda asegurado si, por ejemplo, habiendo seis comuneros, se da a uno una sexta parte física de la cosa común, y a los otros, cinco sextos en comunidad, pues puede ocurrir que vendidos los cinco sextos que se adjudique al grupo mayoritario, valgan más de cinco veces lo que la parte de aquéla quien se le adjudicó un sexto, por haber más facilidades para negociar bien con los cinco sextos vendidos en conjunto, de tal manera que en definitiva cada sexto de los cinco comprendidos en tal conjunto valga más que el sexto que le tocó a quien fue aislado;

VI) Si fuera válida la tesis de los restantes comuneros, se habría descubierto una manera de expulsar a un miembro de una comunidad por la mayoría adversa: podría, en efecto, un miembro de esa mayoría solicitar división en naturaleza o física, y después organizarse con los otros miembros de la mayoría para pedir adjudicación en común de toda la cosa que se trata de dividir con exclusión sólo de la parte que corresponda al comunero que se quiera marginar;

VII) La ley no contempla esta forma de partición, y el derecho procesal es de orden público;

VIII) Todos los autores parten de la base de que la divisibilidad en naturaleza supone que puedan hacerse de la cosa que se trata de dividir tantos lotes como comuneros haya. Podemos hacer algunas citas al respecto"1.

Según la referencia contenida en la página dos del informe de René Abeliuk, el problema consultado se suscita porque Inmobiliaria Security, copropietaria del 15,25\% del predio,

\footnotetext{
${ }^{1}$ Aquí se omiten, para evitar repeticiones, las siete citas efectuadas por el colega José Joaquín Ugarte y el fallo de la Corte de París que a ellas añade.
} 
sostiene que éste no es susceptible de cómoda división, por lo cual pide que se licite, mientras que los restantes comuneros desean permanecer ellos en la comunidad con un lote común, después de retirada la Inmobiliaria Security de la misma, al recibir otro lote individual. Esto no sería jurídicamente posible.

En efecto, es ilegal que el predio, materia de la comunidad o copropiedad en el juicio arbitral de partición que se tramita ante Miguel Leighton, se adjudique en un lote a Inmobiliaria Security, manteniéndose la comunidad sobre el resto de la superficie del predio, entre los otros indivisarios. Como bien lo resolvió la E. Corte Suprema, el 29 de abril de 1954:

"Que, respetando el principio de la igualdad en la repartición, el juez compromisario, a falta de acuerdo entre los indivisarios, que es la primera regla a que debe sujetarse, debe formar los lotes de tal manera que a cada uno de los comuneros toque un lote en el bien común y que dicho lote guarde proporción con los derechos que tiene"2.

Antes, la I. Corte de Apelaciones de Santiago se había pronunciado de modo parecido:

${ }^{2}$ Considerando tercero de la sentencia que declaró sin lugar el recurso de casación en el fondo. El destacado es nuestro. Revista de Derecho, Jurisprudencia y Ciencias Sociales, tomo 51, Santiago, 1954, primera parte, sección 1, p. 86.
"El pensamiento fundamental del sistema de distribución de los bienes hereditarios ideado por el legislador, es que los herederos reciban en especie su cuota hereditaria, para lo cual es necesario, por medio de la tasación e hijuelación en su caso, que los bienes se dividan materialmente, $a$ fin que toque una parte a cada heredero..."3.

La regla jurídica formulada en los fallos de nuestros tribunales superiores, a los cuales recién hice referencia, según la cual en la partición deben formarse tantos lotes cuantos sean los comuneros, para repartirlos entre todos éstos (y dejando aquí de lado el tema que surge cuando los derechos cuotativos son disímiles, del que también se hace cargo la sentencia del 29 de abril de 1954), sólo puede ser soslayada o preterida, si existe voluntad unánime de los indivisarios para proceder de otro modo o, bien, si la especie no admite cómoda división o la división acarrea su depreciación, ya que en este último caso ella será subastada, incluso con admisión de postores extraños. Es lo prescrito, casi textualmente,

${ }^{3}$ Sentencia del 12 de diciembre de 1941, extractada en el Repertorio de legislación y jurisprudencia chilenas. Código Civil, Edit. Santiago, Editorial Jurídica de Chile, 1953, tomo 3, p. 227. También en el libro de Fernando Rozas VIAL y otros, Sucesión por causa de muerte: historia, textos, jurisprudencia y comentarios, Santiago, Editorial Jurídica de Chile, 1985, pp. 750 y 751. 
por la regla primera del artículo 1337 del Código Civil:

"Entre los consignatarios de una especie que no admita cómoda división, o cuya división la haga desmerecer, tendrá mejor derecho a la especie el que más ofrezca por ella; cualquiera de los consignatarios tendrá derecho a pedir la admisión de licitadores extraños; y el precio se dividirá entre todos los consignatarios a prorrata".

Tal regla jurídica es ampliamente reconocida por la doctrina. A los autores que citó el profesor Ugarte en el segundo otrosí de su escrito mencionado, añadiré ahora los siguientes pasajes de eminentes juristas alemanes, franceses y españoles, todos formulados durante el siglo XX.

El Código Civil alemán (BGB del año 1900), junto con establecer que la partición puede pedirse en todo tiempo, acorde al parágrafo 2042, salvo las excepciones de los tres artículos siguientes, se remite a los parágrafos 749 a 758 sobre la disolución de las comunidades. El 752 prescribe:

"La división de la comunidad se realiza por división in natura... La distribución de partes iguales entre los partícipes se realiza mediante sorteo".

El 753-1 añade:

"Si la división in natura es imposible, la disolución de la comunidad se realiza mediante la venta del objeto común..."

En el más célebre Tratado de Derecho Civil alemán, uno de sus autores escribe:

"1. En primer lugar, pues, ha de aplicarse la división natural; es decir, ha de verse si el objeto común o los objetos, en caso de ser varios, se puede descomponer en tantas partes como las participaciones de los interesados, sin menoscabo de su valor. 2. Cuando la división natural está excluida, la comunidad se extingue procediendo a la venta y a la distribución del producto que se obtenga" ${ }^{5}$.

En Francia, los hermanos Henri, Léon y Jean Mazeaud explican que cuando se ordena por la justicia ordinaria la partición judicial, en la resolución se nombra un juez-comisario (partidor) y un notario, salvo que los comuneros los hubiesen designado. En traducción libre mía:

Después de establecida la masa partible por el notario, debe procederse a la composición de los lotes. Éstos

${ }^{4}$ Emilio Eiranova, Código Civil alemán comentado, Madrid, Ed. Marcial Pons, 1998.

${ }^{5}$ Ludwig Enneccerus, Theodor KipP y Martin Wolff, Tratado de Derecho Civil, traducción de la undécima revisión de Helmut Coing, Barcelona, Ed. Bosch, 1976, tomo V- $2^{\circ}$ : Derecho de Sucesiones por Theodor Kipp, p. 273. 
se sortean, salvo acuerdo unánime para efectuar un reparto amistoso de los lotes. La operación más difícil de realizar en la partición es la composición de los lotes. La idea es que los bienes se repartan en naturaleza, componiendo los lotes equivalentes que se distribuirán entre los interesados. La venta es excepcional. En el caso de un inmueble se procederá a licitarlo sólo si no puede ser cómodamente dividido (nuevo artículo 827 del Code Civil).

"A la difficulté de partager l'inmeuble, on assimile la perte de valeur qui résulterait de son fractionnement's.

Otros dos insignes civilistas franceses, Marcel Planiol y Georges Ripert indican:

"Deberán formarse tantos lotes como herederos intervengan en la partición"”.

El director de mi tesis doctoral, catedrático Jacques Flour, acota:

"los inmuebles no deben ser vendidos sino cuando no pueden dividirse en naturaleza,

${ }^{6}$ Henri, Jean et León Mazeaud, Leçons de Droit Civil, $4^{\mathrm{a}}$ ed., Paris, Ed. Montchrestien, 1982, tome 4, vol. 2: Sucesiones y liberalidades, No 1720 y 1721, pp. 912 y 913.

${ }^{7}$ Marcel Planiol y Georges Ripert, Tratado práctico de Derecho Civil francés, traducción de Mario Díaz, La Habana, Ed. Cultural, 1933, 14 tomos, tomo 4: Las sucesiones, $\mathrm{N}^{\circ}$ 526, p. 586 caso desgraciadamente frecuente" ${ }^{8}$ Sic.

En igual sentido ${ }^{9}$.

En España, el profesor de Derecho Civil en la Universidad Complutense de Madrid, y miembro de número de la Real Academia de Jurisprudencia y Legislación, Manuel Albaladejo García, al referirse a la formación de los lotes para su atribución a los indivisarios, ni remotamente sugiere o alude a que se mantenga la comunidad o la copropiedad entre algunos de ellos, efectuándose una partición parcial sólo al copartícipe que saldría de la comunidad o dejaría de formar parte de ella. Antes bien, expresa:

"Si todos los herederos lo son por partes iguales, se formarán lotes todos de igual valor, que después se atribuirán a aquéllos por acuerdo o por sorteo" 10 .

Espero que los antecedentes anteriores sirvan para respaldar las impecables ideas jurídicas expuestas en el escrito individualizado al comienzo.

${ }^{8}$ Jacques Flour et Henri Souleau, Droit Civil. Les Successions, ciudad, Ed. Armand Colin, 1982, Nº 424, p. 269.

${ }^{9}$ Philippe Malaurie, Cours de Droit Civil. Les Successions. Les Liberalités, Deuxième éd., Paris, Cujas, 1992, No 947, p. 482.

${ }^{10}$ Manuel Albaladejo García Curso de Derecho Civil, $5^{\text {a }}$ ed., Barcelona, Ed. Bosch, 1994, tomo v, p. 168. 
BibliografÍA

Albaladejo García, Manuel, Curso de Derecho Civil, $5^{\text {a }}$ ed., Barcelona, Ed. Bosch, 1994, tomo V

Eiranova, Emilio, Código Civil alemán comentado, Madrid, Ed. Marcial Pons, 1998.

Enneccerus, Ludwig, Theodor Kipp y Martin WolfF, Tratado de Derecho Civil, traducción de la undécima revisión de Helmut Coing, Barcelona, Ed. Bosch, 1976, tomo v- $2^{\circ}$ : Derecho de Sucesiones por Theodor Kipp.

Flour, Jacques et Henri Souleau, Droit Civil. Les Successions, ciudad, Ed. Armand Colin, 1982.

Malaurie, Philippe, Cours de Droit Civil.
Les Successions. Les Liberalités, Deuxième éd., Paris, Cujas, 1992.

Mazeaud, Henri, Jean et Léon, Leçons de Droit Civil, $4^{\mathrm{a}}$ ed., Paris, Ed. Montchrestien, 1982, tome 4, vol. 2: Sucesiones y liberalidades.

Planiol Marcel y Georges RiPert, Tratado práctico de Derecho Civil francés, traducción de Mario Díaz, La Habana, Ed. Cultural, 1933, 14 tomos.

Repertorio de legislación y jurisprudencia chilenas. Código Civil, Edit. Santiago, Editorial Jurídica de Chile, 1953

Revista de Derecho,Jurisprudencia y Ciencias Sociales, tomo 51, Santiago, 1954

Rozas Vial, Fernando y otros, Sucesión por causa de muerte: historia, textos, jurisprudencia y comentarios, Santiago, Editorial Jurídica de Chile, 1985. 